\title{
Wolf food habits and wild ungulate availability in the Foreste Casentinesi National Park, Italy
}

\author{
Luca MATTIOLI, Marco APOLLONIO ${ }^{1}$, Vito MAZZARONE \\ and Ettore CENTOFANTI
}

\begin{abstract}
Mattioli L., Apollonio M., Mazzarone V. and Centofanti E. 1995. Wolf food habits and wild ungulate availability in the Foreste Casentinesi National Park, Italy. Acta Theriologica 40: 387-402.

We investigated wolf Canis lupus Linnaeus, 1758 food habits in northern Apennines by examining 240 scats collected between 1988 and 1992 . In the same area we also estimated densities of the most common wild ungulates. Wild ungulates were the main prey of the wolf and accounted for more than $92 \%$ of both frequencies of occurrence and mean percentage volume. During our study period we observed a decrease in the use of roe deer and an increase in the use of wild boar. Moreover selection of wild boar by wolves increased too, but selection of roe deer decreased by almost $400 \%$, with moderately fluctuating deer densities. The impact of predation was generally greatest on young animals. Roe deer fawns and red deer calves were predated 3.14 and 2.18 times respectively more than available. Wild boar also were predated mainly in their first year but more often from 6 months of age than before.

D.R.E.Am. Italia, Via Roma 174, Ponte a Poppi (Arezzo), Italy (LM, VM); Dipartimento di Scienze del Comportamento Animale e dell'Uomo, Via Volta 6, 56126 Pisa, Italy (MA, EC)

Key words: Canis lupus, ungulates, food habits, Italy
\end{abstract}

\section{Introduction}

Wolves Canis lupus Linnaeus, 1758 have been extirpated in most of Western Europe in our century but maintained viable populations remain in Spain, Portugal and Italy (Boitani and Ciucci 1993, Francisci and Guberti 1993, Petrucci-Fonseca and Promberger 1993, Vila et al. 1993). Even in those countries, wolves have faced impoverished ecological conditions, generally characterized by the destruction of their natural prey species: wild ungulates. Under these circumstances wolves have shown their considerable ecological plasticity surviving on various food sources, many of anthropogenic origin such as domestic ungulates (cf Ragni et al. 1982). In extreme situations, garbage from unmanaged dumps has comprised a significant portion of wolf diet, eg in an area of central Italy about 20 years ago (Boitani 1982).

${ }^{1}$ Corresponding author: Marco Apollonio, Dipartimento di Scienze del Comportamento Animale e dell'Uomo, Universita' di Pisa, Via Volta 6, 56126 Pisa, Italy 
Currently ecological condition in western Europe are improving and both wild ungulate and wolf populations are increasing (Braza et al. 1989, Apollonio, in press, for ungulates; Telleria and Saez-Royuela 1989, Francisci and Guberti 1993 for wolf). As a result wolf diets vary in western Europe as a function of wild ungulates densities (Brana et al. 1982, Salvator and Abad 1987, Meriggi et al. 1991, Matteucci 1993, Patalano and Lovari 1993). Predator-prey relatioships between wolves and wild ungulates in western Europe are beginning to assume the same importance as in North America (Fritts and Mech 1981, Peterson et al. 1984, Ballard et al. 1987) and the wolf's role in the regulation and/or control of wild ungulate populations (Mech and Karns 1977, Gasaway et al. 1983) may be increasing in some western European ecosystems.

We present data on wolf food habits in a northern Apennines area where wild ungulates are the almost exclusive prey and wolves have always been present, although at different densities (Matteucci 1993). We evaluate annual differences in the use of prey species, and how use is correlated with time during the study period, and we compare prey use with their availabilities. Finally, we analyze the impact of wolf predation on the age structure of prey species.

\section{Study area}

We evaluated wolf presence in 25600 ha in the Apennines between Tuscany and Romagna, Italy, for the most part included the Foreste Casentinesi National Park. The area was delimited by the

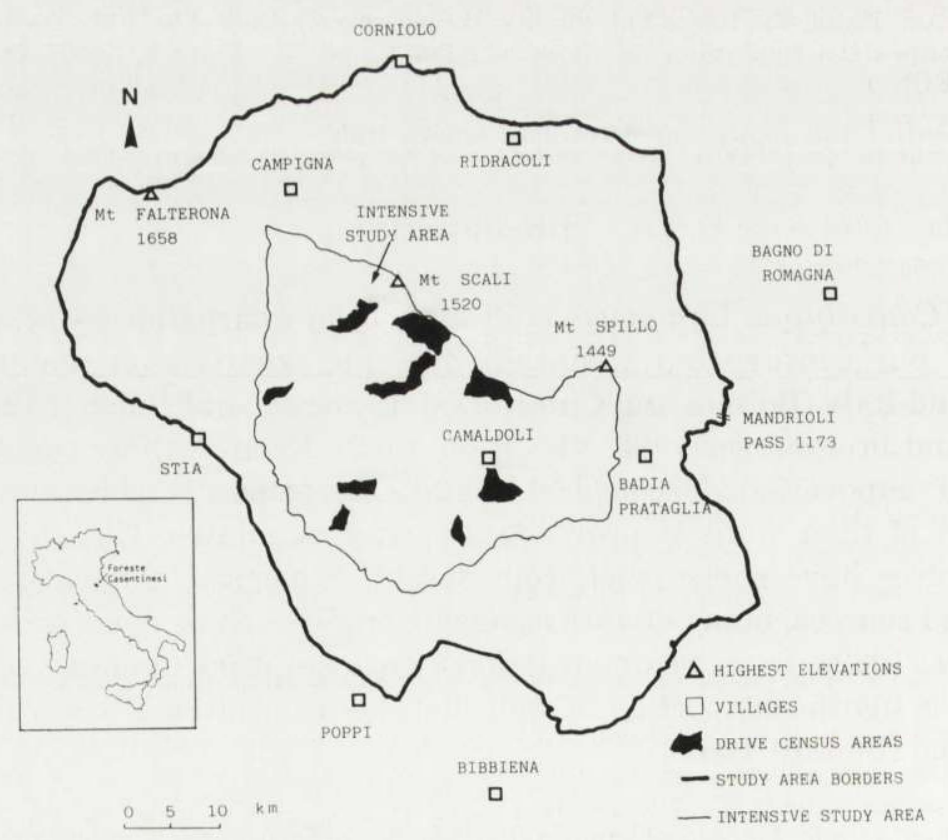

Fig. 1. Study area. 
Monte Falterona (NW) and the Passo dei Mandrioli (SE) (Fig. 1). Collection of wolf scats and evaluation of densities and population structures of primary prey species were limited to an intensive study area of 8780 ha on the Tuscan side of the Foreste Casentinesi $\left(43^{\circ} 48^{\prime} \mathrm{N}, 11^{\circ} 49^{\prime} \mathrm{E}\right)$. This area ranged from 400 to $1520 \mathrm{~m}$ a.s.l., with a mean annual temperature of $8^{\circ} \mathrm{C}$ and a mean snow cover of 94 days at $1100 \mathrm{~m}$ a.s.l. (Padula 1988). The main study area was divided in two parts: $>700 \mathrm{~m}$ a.s.l. with 95\% forest cover consisting of Quercus-Tilia-Acer and Fagus-Abies (Schmidt 1963), closed to hunting, and without human settlements and $<700 \mathrm{~m}$ a.s.l. with a mixture of Quercus pubescens coppice woods $(42 \%)$, pastures and cultivated fields, some villages present, and open to hunting. Four ungulates are present: red deer Cervus elaphus, roe deer Capreolus capreolus, fallow deer Dama dama, and wild boar Sus scrofa. Mouflon Ovis orientalis musimon were present until a few years ago, but they are now absent from the study area. Domestic ungulates were raised only below $700 \mathrm{~m}$ a.s.l. (in 1990 about 960 sheep and a few cows and horses were present). No unmanaged garbage dumps were present, and stray dogs were only occasionally observed in summer and during the hunting season; their presence seemed limited to only a few months.

\section{Methods}

\section{Fecal analysis}

From May 1988 through October 1992, we collected 240 wolf scats along transects, from 700 to $1500 \mathrm{~m}$ a.s.l. that were travelled every $3-5$ weeks. Scats were preserved in plastic bags at $-18^{\circ} \mathrm{C}$. Scats were washed in a sieve $\left(1 \mathrm{~mm}\right.$ mesh), and the remaining material was dried at $40^{\circ} \mathrm{C}$ for 24 hours. Identification of mammal remains was based on a reference collection of hairs and bones of adults and young prey species. For rodents and lagomorphs, we used microscopic taxon-specific characteristics of hairs (Debrot et al. 1982). Scats that contained recognizable bone fragments and teeth allowed us to determine prey age class ( $>$ or $<$ than 12 months old) via dimension and degree of ossification of bone fragments. For red deer, we determined age of individual prey from May to October from hair characteristics, but to age red deer remains in scats collected from November to April, we used bone fragments because hair became useless for discrimination. We assumed that an adult red deer was the prey when scats contained only hair because bone fragments of adults were unlikely to occur in scats. For roe deer, only bone fragments were used for aging prey throughout the year.

To calculate relative numbers of prey, remains of youngs were assigned to different weight classes in relation to the collection time of the scats, while remains of adult were given a mean value weighted on the population structure of each species (Floyd et al. 1978). Body weights were obtained by locally collected data for roe deer, from Apollonio and Toso (1988) for fallow deer, and from S. Mattioli (unpubl. data) for red deer. Wild boar samples are difficult to age on the basis of collection time for the long breeding season, so we ranked them by weight classes on a 5 - $\mathrm{kg}$ scale on the basis of bones remains. To do that, we calculated growth curves from a collection of 5 skeletons from individuals of known weight (Fig. 2).We used only measures of bones whose curves fitted with the equation we had used to

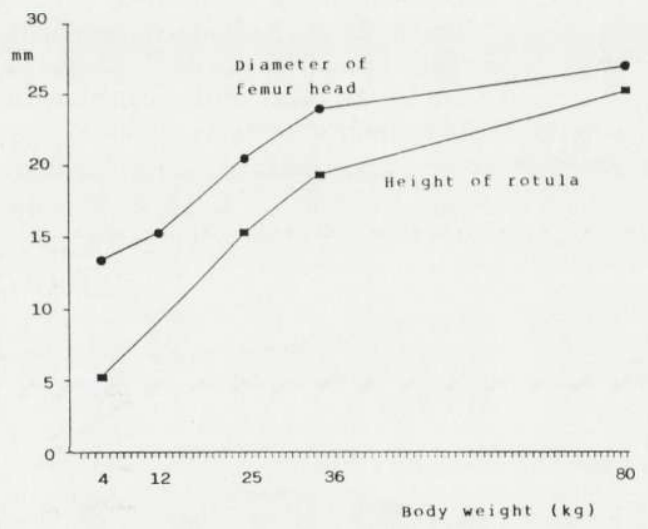

Fig. 2. Curves relating weight and diameter of femur head and height of rotula in wild boar. 
describe them with a $p<0.005$ These data were translated into age classes ( $>$ or $<$ year old) using weights of 38 boars of known age shot in study area. Only one out the 12 piglets (ie animals below 12 months of age) in this sample was over $28 \mathrm{~kg}$, so boars below this weight were classified as $<1$ year old. Similar to red deer, scats containing only wild boar hair were attributed to weight classes $>13 \mathrm{~kg}$ proportional to their presence in the sample. The consequence of this procedure was that roe deer and wild boar data were comparable all year long, but red deer data were biased toward adults in winter. A general bias toward adults resulted from attributing all scats without hair to this age class. In each scat, we attributed volume values of $25,50,75$, and $100 \%$ to single items.

Vegetable materials, with the exception of fruits, were not included in volume calculations (they represented only trace amounts in all but one case) following Fritts and Mech (1981), because they were undigestible and probably ingested by chance (Patalano and Lovari 1993). For each food item, we calculated frequency of occurrence and mean percent volume in the whole sample. For the four wild ungulate species and domestic sheep, we calculated percentage biomass and relative number of prey following Floyd et al. (1978).

\section{Density estimates and population structure of wild and domestic prey species}

Density of roe deer before parturition was estimated from 1988 to 1993 by drive censuses (C.E.M.A.G.R.E.F. 1984, Lovari et al. 1989) in the last 10 days of May on 6 permanent sample sites in 405 ha. Density after parturition was calculated on the basis of the relative frequency of females in the population, and their fertility was obtained from a sample of 25 females shot each year, in or close to the study area (Lovari et al. 1991) (Table 1).

Density of wild boar was estimated on the basis of data collected during the drives mentioned above (Table 1). We could not use other census techniques because of habitat structure and the impossibility of maintaining feeding stations. Density in late May reflected the highest annual density in the study area, because almost all births had occurred before that time (Pedone et al. 1991).

Red deer censuses were conducted from 1988 to 1992 in the late September by counting roaring males in 5103 ha $(76.2 \%$ of the main study area) (Mazzarone et al. 1991). Density after birth was calculated by adding the number of fawns, calculated on the basis of the fertility rates for western Europe, to the population $>1$ year of age (Table 1). We had no data on fallow deer. Domestic sheep numbers in the study area were obtained by the National Institute of Statistic data on husbandry activities from 1986 to 1990 .

Table 1. Estimated ungulates density $(n / 100 \mathrm{ha})$ before and after parturitions in the intensive study area. ${ }^{a}$ Calculated from drive-census data (May) excluding piglets, ${ }^{\mathrm{b}}$ obtained from drive-census in May, ${ }^{\mathrm{c}}$ calculated from roaring census excluding calves, ${ }^{d}$ calculated from drive-census data and fertility rate from Lovari et al. $1991,{ }^{e}$ calculated from roaring census and fertility rate from S. Mattioli, in prep.

\begin{tabular}{|c|c|c|c|c|c|}
\hline Species & 1988 & 1989 & 1990 & 1991 & 1992 \\
\hline \multicolumn{6}{|c|}{ Before parturition } \\
\hline Wild boar ${ }^{a}$ & 8.2 & 9.3 & 4.8 & 3.0 & 5.7 \\
\hline Roe deer ${ }^{b}$ & 15.5 & 17.3 & 19.0 & 17.3 & 13.3 \\
\hline Red deer ${ }^{c}$ & 2.7 & 3.3 & 3.5 & 4.3 & 4.5 \\
\hline \multicolumn{6}{|c|}{ After parturition } \\
\hline Wild boar ${ }^{\text {b }}$ & 20.3 & 21.4 & 12.8 & 5.3 & 13.6 \\
\hline Roe deer ${ }^{d}$ & 25.4 & 28.3 & 32.0 & 26.5 & 22.2 \\
\hline Red deer ${ }^{\mathrm{e}}$ & 3.9 & 4.8 & 5.1 & 6.1 & 6.4 \\
\hline
\end{tabular}


Population structure data were collected on monthly transects covered each month and during observation sessions from elevated blinds within the study area from 750 to $1500 \mathrm{~m}$ a.s.l. For roe deer we recognized four sex-age classes: adult males ( $>2$ years), yearling males, adult females, and young. Sex ratio was defined only by data from closely $(5-20 \mathrm{~m})$ observed deer during drives, and was about 0.67 males to females. For red deer we distinguished five sex-age classes: adult males ( $>5-6$ years), young males (2-4 years), yearling males, females, and calves. For wild boar we distinguished only between piglets ( $<12$ months) and adults ( $>12$ months). The highest percentage of piglets in the population occurred in May. We could not collect enough data on the fallow deer population structure. We also had no information on the sheep/lamb ratio on farms surrounding the study area because it was extremely variable in relation to market demands.

\section{Statistical analyses}

Trophic niche breadth was evaluated with Levin's index (1) applied to the mean percentage volume of food categories in the whole diet (cited in Ricklefs 1980: 745-746). Trends of occurrence of different prey species in wolf diets from winter 1988 through summer 1992, and correlations between prey availability of each ungulate and its occurence in wolf diets were evaluated with Spearman's rank correlation. That test was used to evaluate changes in selection through time for different ungulate prey and correlations between pairs or groups of species in the wolf diets. The impact of wolf predation on the age structure of each prey population was expressed with the structure coefficient of selection (SCS; 2). Differences between availability of adults and youngs in the populations of different prey species and their occurrence in wolf diets, were expressed as percentages and evaluated with the $\chi^{2}$-test using the number of scats containing remains of preys of known age (from now on "aged scats") of each species.

Levin Index: $\quad \mathrm{B}=1 / \sum_{i=1}^{n} p^{2} i$

$$
\mathrm{SCS}=\frac{\text { number of adults } / \text { number of young in the population }}{\text { number of adults } / \text { number of young in wolf scats }}
$$

SCS $=1-$ no selection, $\mathrm{SCS}>1-$ selection for young, $\mathrm{SCS}<1-$ selection for adults.

\section{Results}

In an area of 25600 ha that included our intensive study area, (see Study area), we estimated the presence of at least 2 reproductive pairs, in both 1990 and in 1992 using the wolf-howling technique (Harrington and Mech 1982). We suspected the presence of a third pair in 1990, but we could not confirm it. Wolf presence in this area appeared constant; we observed pairs with pups in 1986, 1991 and 1992, and from 1984 to the present wolves were constantly observed. Moreover three dens were found from 1986 to 1992. In this area, wolves have been present since historical times (Cagnolaro et al. 1974, Matteucci 1993). Numbers appear to have experienced a decline during the 1970s, but the species was never completely extirpated because scattered observations also were recorded during that time.

Wild ungulates were the primary prey of wolves and accounted for $>92 \%$ of both frequencies of occurrence and mean percent volume (Table 2). Sheep were 
Table 2. Composition of wolves diet in the intensive study area. ${ }^{a}$ In case of more than one prey item, proportion of each prey type were estimated and summed to the scats containing only that prey type, calculated on wild boar, roe der, red deer, fallow deer and sheep ( $98.2 \%$ of the total volume) only, c calculated according to Floyd et al. 1978.

\begin{tabular}{|c|c|c|c|c|c|c|}
\hline Food items & $\begin{array}{c}\text { Number of } \\
\text { scats }^{\mathrm{a}} \\
n\end{array}$ & $\begin{array}{c}\text { Frequency } \\
\text { of } \\
\text { occurrence } \\
\%\end{array}$ & $\begin{array}{l}\text { Mean relative } \\
\text { volume in the } \\
\text { total sample } \\
\text { \% }\end{array}$ & $\begin{array}{c}\text { Mean relative } \\
\text { volume in the } \\
\text { sample }^{\mathrm{b}} \\
\%\end{array}$ & $\begin{array}{c}\text { Relative } \\
\text { biomass } \\
\text { eaten }^{\mathrm{c}} \\
\%\end{array}$ & $\begin{array}{c}\text { Relative } \\
\text { number of } \\
\text { preys eaten } \\
\%\end{array}$ \\
\hline Wild boar & 107.6 & 52.5 & 44.8 & 45.6 & 39.9 & 47.1 \\
\hline Roe deer & 78.9 & 38.8 & 32.9 & 33.5 & 25.2 & 37.5 \\
\hline Red deer & 26.3 & 14.6 & 11.0 & 11.2 & 24.4 & 7.2 \\
\hline Sheep & 13.7 & 6.3 & 5.7 & 5.8 & 6.0 & 4.6 \\
\hline Fallow deer & 9.2 & 5.0 & 3.9 & 3.9 & 4.5 & 3.7 \\
\hline Cattle or horse & 1.0 & 0.8 & 0.4 & - & - & - \\
\hline Hare & 1.3 & 0.8 & 0.5 & - & - & - \\
\hline Dormouse & 0.5 & 0.4 & 0.2 & - & - & - \\
\hline Microtines & 0.8 & 0.8 & 0.3 & - & - & - \\
\hline Fruits & 0.7 & 0.8 & 0.3 & - & - & - \\
\hline Total & 240.0 & 120.8 & 100 & 100 & 100 & 100 \\
\hline
\end{tabular}

the only domestic species that had some importance in wolf diets and reached about 6\%; all other items were quantitatively unimportant (Table 2). Most scats $(79.2 \%)$ consisted of remains of only one prey species, $19.6 \%$ contained two species, and only $1.2 \%$ contained three prey species. Mean weight of ungulate prey species was correlated positively with the percentage of mixed scats that contained this species (Spearman rank correlation test, $r_{\mathrm{S}}=0.974 p<0.05$, one-tailed). To test if local densities and species diversity in ungulates were correlated directly with scat composition, we compared a subsample of scats collected from May 1991 through August 1992 in our study area $(n=60)$ with a sample collected in the same time in another area, placed west of our study area (Mt Falterona) ( $n=26)$, which was characterized by higher density of wild boar than cervids that were scarce. Differences significantly reflected on scat's composition that were different $\left(\chi^{2}=7.7, p<0.02\right)$ being wild boar more common in the scats of Mt Falterona.

Trophic niche breath was low if computed with all wild ungulates pooled into one category as is commonly done in similar studies. No clear differences among cold and warm seasons were found (Table 3).

Taking into account subsequent warm (from May to October) and cold (from November to April) six months periods, we examined if there were significant trends in ungulate use by wolves during the entire study. Only roe deer showed a significant decrease $\left(r_{\mathrm{S}}=-0.81,0.02<p<0.05\right)$, wild boar showed on the contrary an almost significant increasing trend $\left(r_{\mathrm{S}}=0.069,0.1>p>0.05\right)$, and all the others showed no trends (Fig. 3). 
Table 3. Trophic niche breadth of the wolf in subsequent hot and cold seasons of the study. B1 - food categories: wild ungulates, domestic ungulates, lagomorphs, rodents and fruits; B2 - food categories: wild boar, roe deer, red deer, fallow deer, sheep, other domestic ungulates, lagomorphs, rodents and fruits; Vol \% - mean percent volume; Occ - frequency of occurrence.

\begin{tabular}{|c|c|c|c|c|c|}
\hline \multirow{3}{*}{ Period } & \multicolumn{4}{|c|}{ Niche breadth } & \multirow{3}{*}{$\begin{array}{c}\text { Sample sizes } \\
n\end{array}$} \\
\hline & \multicolumn{2}{|c|}{$\mathrm{B} 1$} & \multicolumn{2}{|c|}{ B2 } & \\
\hline & Vol \% & Occ & Vol \% & Occ & \\
\hline May-Oct 1988 & 1.09 & 0.89 & 2.61 & 2.08 & 33 \\
\hline Nov 1988 - Apr 1989 & 1.12 & 0.76 & 3.20 & 2.16 & 36 \\
\hline Nov 1989 - Apr 1990 & 1.17 & 0.89 & 2.45 & 1.88 & 36 \\
\hline May-Oct 1990 & 1.06 & 0.80 & 2.40 & 1.72 & 9 \\
\hline Nov 1990 - Apr 1991 & 1.16 & 0.60 & 3.17 & 1.74 & 38 \\
\hline May-Oct 1991 & 1.62 & 1.08 & 4.67 & 3.33 & 29 \\
\hline Nov 1991 - Apr 1992 & 1.05 & 0.78 & 1.99 & 1.52 & 30 \\
\hline May-Oct 1992 & 1.07 & 0.93 & 1.58 & 1.39 & 29 \\
\hline Mean & 1.17 & 0.84 & 2.76 & 1.98 & \\
\hline
\end{tabular}

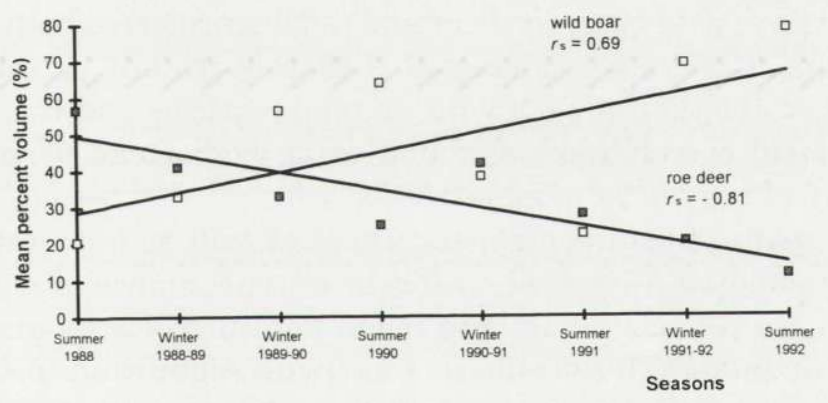

Fig. 3. Mean percent volume of wild boar and roe deer in wolves scats plotted against successive warm and cold seasons.

To test if there was any selective trend in the predation on the main ungulate prey species, we plotted the ratio between relative number of prey in scats and their population density against years, computing a Spearman correlation test to see if the species considered were increasingly or decreasingly utilized with respect to their density. Wild boar showed a positive correlation $\left(r_{\mathrm{S}}=0.9, p=0.1\right)$ indicating that in spite of a decreasing density this species was increasingly utilized. On the contrary roe deer showed an opposite trend $\left(r_{\mathrm{S}}=-0.974, p=0.06\right)$. During the study period this species actually maintained a fluctuating density with a moderate decrease in the last two years which corresponded to an almost $400 \%$ decrease in occurrence in wolf diets. Red deer did not show any significant trend with a fluctuating use in face of a steady moderate increase in density (Fig. 4). 


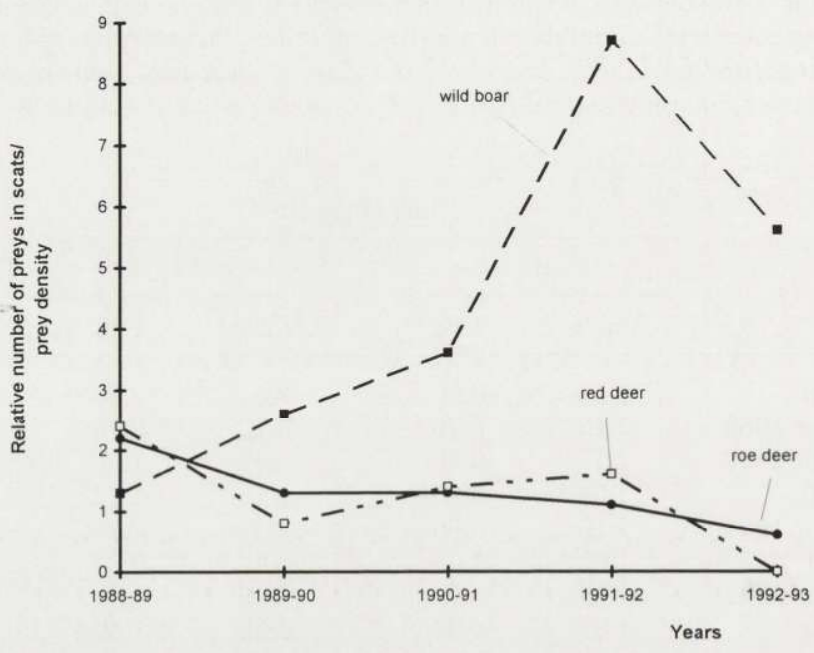

Fig. 4. Prey selection by the wolf indicated as (ordinate) ratio between relative number of preys in scats and population density of wild boar, red deer, and roe deer plotted against years (abscisse).

Using densities of wild boar, roe deer and red deer referred both to the following and the subsequent years we calculated if there were any correlations between the immediate availability of each wild ungulate species and the use of it by the wolf. No significant correlation was found using both mean percent volume and relative number of prey $\left(-0.6<r_{\mathrm{S}}<0.36, n=5\right)$.

To evaluate relatioships among occurrences of wild and domestic ungulates in wolf diets, we computed a Kendall coefficent of concordance over the eight warm and cold six month periods using both mean percent volumes and biomasses for each species of ungulate. This coefficent was highly significant $(p<0.001)$ for both volume and biomass, which indicated that the relative rank of preys in wolf diets changed during our study (Table 4). To test if increased use of one prey species corresponded to decreased use of another, we evaluated correlations among ungulate occurrence in wolf diets in the 8 six months periods of our study. First,

Table 4. Changes in the importance of different ungulate species in wolf diets during the study expressed in mean percent volume.

\begin{tabular}{|c|c|c|c|c|c|c|c|c|}
\hline Period & $\begin{array}{l}\text { No of } \\
\text { scats }\end{array}$ & $\begin{array}{l}\text { Wild } \\
\text { boar }\end{array}$ & $\begin{array}{l}\text { Roe } \\
\text { deer }\end{array}$ & $\begin{array}{l}\text { Red } \\
\text { deer }\end{array}$ & Sheep & $\begin{array}{c}\text { Fallow } \\
\text { deer }\end{array}$ & $\begin{array}{c}\text { Other } \\
\text { domestic }\end{array}$ & Other \\
\hline May 1988 - Apr 1989 & 68 & 26.5 & 48.1 & 15.8 & 4.0 & 4.4 & 0.7 & 0.35 \\
\hline May 1989 - Apr 1990 & 37 & 55.4 & 31.0 & 5.4 & 4.7 & - & - & 2.7 \\
\hline May 1990 - Apr 1991 & 47 & 42.1 & 37.5 & 10.7 & 2.1 & 3.2 & - & 2.1 \\
\hline May 1991 - Apr 1992 & 59 & 44.9 & 23.2 & 14.4 & 12.3 & 4.2 & 0.85 & 1.7 \\
\hline May 1992 - Oct 1992 & 29 & 78.4 & 11.2 & - & 3.4 & 6.9 & - & - \\
\hline
\end{tabular}




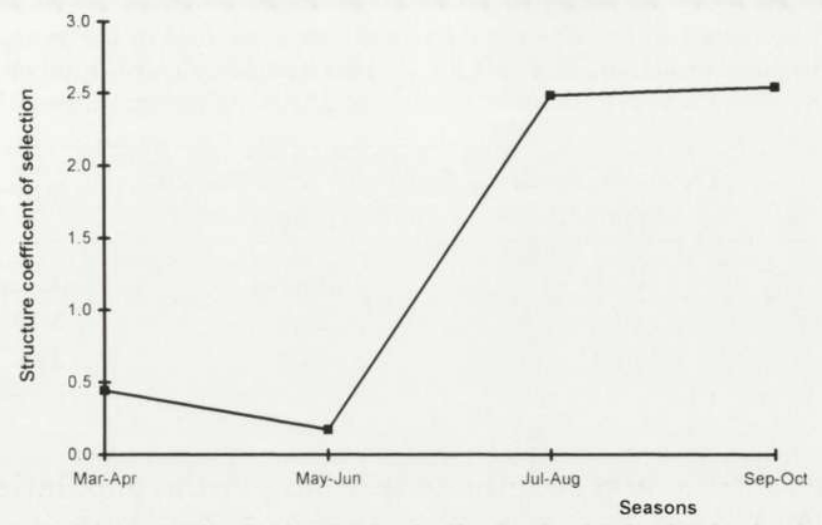

Fig. 5. Structure coefficent of selection for wild boar in different months.

we took into account wild vs domestic ungulates and found significant correlations for mean percent volumes $\left(r_{\mathrm{S}}=-0.738, p=0.05\right)$ and biomasses $\left(r_{\mathrm{S}}=-1\right.$, $p<0.0001)$. Then, we evaluated all cervids vs wild boar and vs domestic ungulate; their use was inversely correlated with wild boar $\left(r_{\mathrm{S}}=-0.928, p<0.005\right.$ for both mean percent volume and biomass) but not with domestic ungulates. Finally, we considered pairwise comparisons for the six ungulate species. The only significant pairs were (1) wild boar vs roe deer $\left(r_{\mathrm{S}}=-0.833, p=0.02\right)$ and wild boar vs red deer $\left(r_{\mathrm{S}}=-0.785, p=0.05\right)$ with mean percent volume, and (2) wild boar vs red deer $\left(r_{\mathrm{S}}=-0.809,0.05>p>0.02\right)$ with biomass.

Young animals generally were most affected by wolf predation. Expressed as the relative number of prey eaten, in 57 "aged scats" containing roe deer, fawns represented $66.2 \%$ of the prey, in 31 scats containing red deer, calves represented $49 \%$, and in 77 scats containing wild boar $85.5 \%$ were small animals $(<28 \mathrm{~kg})$, presumably below one year of age. The structure coefficent of selection (SCS),

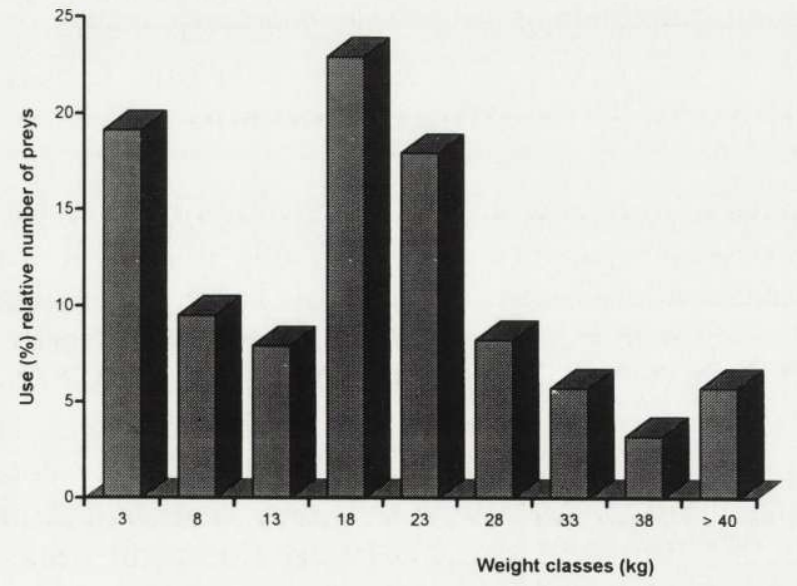

Fig. 6. Frequency distribution of wild boar weight classess in wolf diet obtained by scats analysis. 
Table 5. Predation on fawns and adults roe deer in different periods of the year. * If we assume that $50 \%$ of fawns is already born, than SCS $=1.25,{ }^{a}$ expressed as relative number of prey (Floyd et al. 1978), ${ }^{b}$ obtained by direct observations, ${ }^{c}$ structure coefficent of selection (see Methods).

\begin{tabular}{lcccc}
\hline Months & $\begin{array}{c}\text { Percent of fawns } \\
\text { in prey }\end{array}$ & $\begin{array}{c}\text { Percent of fawns present } \\
\text { in the population }\end{array}$ & SCS $^{\mathrm{b}}$ & $n$ \\
\hline May-June* $^{*}$ & 25.6 & Unknown & Unknown & 10 \\
July-October & 81.1 & 43.0 & 5.78 & 14 \\
November-April & 61.1 & 34.0 & 3.03 & 33 \\
\hline
\end{tabular}

which accounted for the actual ratio adult/young in the populations, was 3.14 for roe deer and 2.87 for red deer, indicating that youngs of both species were preyed on about three times more than adults with respect to their availabilies. Wild boar had a SCS of 1.8; young boars were preyed on almost twice as often as adults. Statistical evaluation of the differences between availability and use of the young gave significant results for wild boar $\left(\chi^{2}=7.74, p<0.01\right)$ and roe deer $\left(\chi^{2}=7.65\right.$, $p<0.01)$ but surprisingly not for red $\operatorname{deer}\left(\chi^{2}=2.71, p=0.1\right)$. Seasonal variations in SCS could be evaluated for wild boar and roe deer. Predation of wild boar was unbalanced against boars $>1$ year in the first half of the year and then heavier on small animals in the second half (Fig. 5). Fully grown (>40 kg) wild boar, however, were a small part of wolf diets, suggesting that piglets and subadults constituted the bulk of wild boar occurrence in wolf diets (Fig. 6). Young roe were more common in wolf diets from July through October and from November through April. However, some data from May through June suggested a limited predation on newborns (Table 5). For red deer we were unable to give fully comparable results given the differences in the analyses of scats from the two periods of the year (see Methods). Althogh not statistically significant, results seemed to suggest that calves were preyed on less in the second half of the year; however, a bias toward adults due to methodology should be acknowledged.

\section{Discussion}

The percentages of wild ungulates in wolf diets in our study area were the highest ever reported in western Europe (Table 6), which was not surprising because of the local availabilities of such preys (Table 1). Feeding habits of wolves in the Foreste Casentinesi were more similar to those in North American (Fritts and Mech 1981, Gasaway et al. 1983) or eastern European (Jędrzejewski et al. 1989, Bibikow 1990) than to western European conditions. However, because improving habitats condition and increasing wild ungulate densities in western Europe, it is probable that our study area may represent a prediction of what could happen in the future in many western European areas rather than representing a relict of old, primeval conditions. 
Table 6. Wild ungulates use by the wolf in western Europe estimated from scats analyses.

\begin{tabular}{llcc}
\hline Area & \multicolumn{1}{c}{ Author/s } & $\begin{array}{c}\text { Collection } \\
\text { period }\end{array}$ & $\begin{array}{c}\text { Wild ungulates fre- } \\
\text { quency of occurrence }\end{array}$ \\
\hline Foreste Casentinesi (Italy) & This study & $1988-1992$ & 94.6 \\
Northern Apennines (Italy) & Meriggi et al. 1991 & $1987-1989$ & 18.0 \\
Abruzzo National Park (Italy) & Patalano and Lovari 1993 & $1981-1983$ & 43.4 \\
Umbria, Valnerina (Italy) & Ragni et al. 1982 & $1977-1982$ & 0 \\
Majella, Abruzzo (Italy) & Boitani 1982 & $1974-1977$ & 0 \\
Province Leon (Spain) & Salvador and Abad 1987 & $1984-1986$ & 35.3 \\
Asturies (Spain) & Brana et al. 1982 & ca 1980 & 39.8 \\
\hline
\end{tabular}

Diet analyses were simplified in our study because of the high percentage of the scats that contained only one species of prey. This allowed an accurate evaluation of biomasses and relative number of prey (Floyd et al. 1978), as has occurred in most North American wolf studies (Fritts and Mech 1981). Differences between our results and those of other western European studies also were emphasized by our low trophic niche breadth (cf Meriggi et al. 1991, Patalano and Lovari 1993). Fruits, rodents and domestic ungulates that have been so abundant in wolf diets in other areas (eg Meriggi et al. 1991) were absent or essentially insignificant in our study, indicating that their use was related to an impoverished ecological situation. These food items were not absent in our study area, but wolves could rely primarily on ungulates for prey.

Scat composition seemed to reflect local differences in abundance of ungulate species in the Foreste Casentinesi. Differences in relative abundances of wild boar and cervids in our intensive study area and Mt Falterona were correspondingly reflected in wolf scats with reasonable confidence, one can thus assume that contents of wolf scats will correspond the local community composition of prey. Analogous observations have been made in North America (Fritts and Mech 1981) and in Europe (Brana et al. 1982).

Wild boar and roe deer had an opposite trend in their occurrence in wolf diet during the five years of our study. The role of these two species as principal prey species reversed from the beginning to the end of our study. This result may be apparently considered similar to observations by Voigth et al. (1976) studying summer food of wolves in Ontario and Frenzel (1974) in the Superior National Forest. White tailed deer Odocoileus virginianus decreased in density in both studies and beaver Castor canadensis in the first study, and both beaver and moose Alces canadensis in the second study increased significantly in wolf diets. However, in our study the increase of wild boar in wolf diets was not due to an increase in wild boar density, that decreased during the study period. As a departure from the general rule of correlation between availability of prey and the level of predation (Shelton 1966, Hall 1971, Kuyt 1972, Fritts and Mech 1981 but see Cowan 1947: 167 for contrary results), increased wild boar use by wolves 
could have been the consequence of the development of a selective preference for this kind of prey together with an analogous but opposite use of roe deer. Causes of differential selection may be that wild boar are more vulnerable than roe deer. Wild boar form groups that are easy to identify. They are relatively slow, in comparison to cervids. Their populations are composed mainly of young animals, that are easy to catch and relatively defenseless. The strategy of selecting the most vulnerable and aboundant prey species where two or more are available has been shown by Mech (1970: 174). It is difficult to explain why the relatively high use of wild boar in the study area apparently developed only recently. A possible explanation is that roe deer were always present in our study area (Crudele 1988, Lorenzini et al. 1993), but wild boar were reintroduced in the 1970s after being absent for at least 80 years and reached high densities in the second half of the 1980 s (ie was not "traditional" prey). This and the possibility that food habits may be perpetuated between generations because packs sometimes have distinct prey preferences (Holleman and Stephenson 1981) may explain why wolves have "discovered" wild boar so late and why use of this prey is now increasing despite declining density. A concordant result is the lack of correlation of immediate availability of a prey species and its use by the wolf, emphasizing again the delay of reaction to the changes of demographic tendencies of his prey species (Mech and Karns 1977, Gasaway et al. 1983).

Relatioships among different species of ungulates in the wolf diets varied through time. Inverse correlations existed between wild and domestic ungulates and between cervids and wild boar. Moreover, wild boar use was inversely correlated with use of both roe and red deer. These results suggest that wild boar use buffers effects of wolf predation on other ungulates. An equivalent species to the wild boar in terms of reproductive rate, high potential density, and vulnerability does not exist in North American ecosystems, where wolves can cause noncompensatory mortality on cervids (Mech and Karns 1977, Gasaway et al. 1983). However, it should be noted that wild boar do not always assume, where present, a primary importance in wolf diets in western Europe (Brana et al. 1982) or in the Paleartic (Bibikow 1990: 87, Jędrzejewska et al. 1994). To explain that it should be taken into account that body size of wild boar of this population is smaller than central and eastern European ones. So they are probably more vulnerable to wolf predation than the latter.

Low wolf use of domestic ungulates in our study could be due to their low availability, location of farms at the border of the forest (ie marginal areas with respect to wolf presence), active defence of livestock by dogs, and nocturnal housing of livestock. Telleria and Saez-Royuela (1989) in Spain and Fritts and Mech (1981) in North America showed that wolf predation on livestock was rare in natural areas with readily available wild preys. In contrast Patalano and Lovari (1993) found wolves preying on domestic ungulates in central Italy, despite the presence of four wild ungulates, which may be explained by differences in both livestock husbandry and wild ungulates densities. Domestic ungulates were more inter- 
spersed in their study area than in the Foreste Casentinesi. Moreover, wild ungulates, apart from Apennine chamois Rupicapra pyrenaica ornata, had recently repopulated their study area, and neither roe deer nor wild boar were numerous.

Predation on young ungulates in our study area reflected the general rule expressed by Mech (1970: 249), ie wolves kill primarily animals $<1$ year old or those over middle age. Cervids predation in our study reflected the pattern found both for white tailed deer and moose (Thompson 1952, Voigth et al. 1976, Fritts and Mech 1981, Peterson et al. 1984) using scats analyses; ie fawns are preyed more than their availabilities would suggest. Parallel to other published studies cervids fawns were preyed on 2 or 3 times more than they were available. Despite the lack of statistical significance due to small sample size red deer calves were preyed on $>2.5$ times more than were adults relative to their respective availabilities. This was congruent with results based on recovered wolf kills of Bobek et al. (1993) in southern Poland and to the majority of cases presented by Filonov and Kaleckaja (1985) for populations in the former USSR. Wild boar piglets $<6$ month seemed clearly to be less attractive to wolves in our study than 6 - to 12-month-old piglets. Three reasons may explain this: (1) very young piglets are more difficult to find because they spend more time concealed in the farrowing nest; (2) they may be carefully guarded by the mother who maintains close contact with them and warns them of predators in their first months of life; or (3) they may represent a less rewarding or cost effective prey to wolves. These hypotheses are not mutually exclusive and a combination of them may be the most probable explanation. There are very few data on age class selection in wild boar: Filonov and Kaleckaja (1985) found that adult wild boar in three areas in former USSR seemed to be preyed on more (14.3 to $50 \%$ ) than in our area (6\%). However, no data on actual population structure in the former USSR were given, and their data on wolf predation were based on carcasses recovery, a method that can bias actual kill age structure of wild boar to a greater extent than red deer. Seasonal selection of young wild boars occurred in our study area, which appeared to be a direct consequence of preference for half grown piglets. Roe deer fawns also seem to receive increased predation as summer progressed in accordance to Thompson (1952) who suggested that fawn vulnerability increased during summer.

Acknowledgements: We are grateful to S. Lovari, D. Schackleton and M. Festa-Bianchet who gave many useful suggestions on the first draft of this paper. C. Lovari, N. Siemoni, E. Giorgi and F. Castellani helped in field data collection and in results discussion. This research was financially supported by the Comunita' Montana del Casentino (S. Borchi and G. Baldini) and by the Regione Toscana (P. Cerdini). We gratefully acknowledge two anonimous reviewers for their effort in improving concepts and style of our paper.

\section{References}

Apollonio M. and Toso S. 1988. An evaluation of the management of a population of fallow deer and of the consequences on his demografy and biometrical values. Supplementi Ricerche Biologia Selvaggina 14: 525-540. [In Italian] 
Apollonio M. (in press). Changes of habitat quality and human activities in the Apennines region in relation to wolf presence. Atti del Convegno Nazionale "Dalla parte del lupo", Parma, 9 e 10 Ottobre 1992. [In Italian]

Ballard W. B., Whitman J. S. and Gardner C. L. 1987. Ecology of an exploited wolf population in south-central Alaska. Wildlife Monographs 98: 75-81.

Bibikow D. I. 1990. Der Wolf. Die Neue Brehem-Bucherei, No 587 Wittemberg Lutherstadt: 1-333.

Bobek B., Perzanowski K. and Śmietana W. 1993. The influence of snow cover on wolf Canis lupus and red deer Cervus elaphus relationships in Bieszczady Mountains [In: Global trends in wildlife management. B. Bobek, K. Perzanowski and W. L. Regelin, eds]. Świat Press, Kraków-Warszawa: 341-348.

Boitani L. 1982. Wolf management in intensively used areas of Italy [In: Wolves of the world. Perspectives of behavior, ecology and conservation. F. H. Harrington and P. C. Paquet, eds]. Noyes publications, Park Ridge, New Jersey: 158-172.

Boitani L. and Ciucci P. 1993. Wolves in Italy: critical issues for their conservation. [In: Wolves in Europe. Status and perspectives. C. Prombergher and W. Schröder, eds]. Munich Wildlife Society, Munich: 74-90.

Brana F., Brana F., Del Campo J. C. and Palomero G. 1982. Le Loup dans la Cordillere Cantabrique. Acta Biologica Montana 1: 33-52.

Braza F., Varela I., San Jos C. and Cases V. 1989. Distribution actuelle du chevreuil (Capreolus capreolus), du daim (Dama dama) et du cerf (Cervus elaphus) en Espagne. Zeitschrift für Säugetierkunde 54: 393-396.

Cagnolaro L., Rosso D., Spagnesi M. and Venturi D. 1974. Report on wolf distribution in Italy and in Tessin and Graubunden Cantons. Ricerche di Biologia della Selvaggina 59: 1-75. [In Italian]

Centofanti E. and Crudele G. 1993. The presence of wolf (Canis lupus) in relation to ungulates in the Foreste Casentinesi. Not published report of Ministry of Agricolture and Forestry: 1-27. [In Italian]

C.E.M.A.G.R.E.F. 1984. Methodes de recensement des populations de chevreuils. Note technique no 51, Nogent sur Vernisson: 1-65.

Cowan I. T. 1947. The timber wolf in the Rocky Mountain National Parks of Canada. Canadian Journal Research D(25): 139-174.

Crudele G. 1988. The fauna. [In: Le Foreste di Campigna-Lama nell'Appennino tosco-romagnolo. M. Padula and G. Crudele, eds]. Regione Emilia Romagna, Bologna: 325-401. [In Italian]

Debrot S., Fivaz G., Mermod C. and Weber J. M. 1982. Atlas des poils de mammiféres d'Europe. Peseux: Imprimerie de l'Ouest S. A.: 1-208

Filonov U. and Kaleckaja M. L. 1990. [In: Der Wolf. D. I. Bibikov, ed]. Die Neue Brehm-Bucherei, No 587 Wittemberg Lutherstadt: 93.

Floyd T. J., Mech L. D. and Jordan P. A. 1978. Relating wolf scat contents to prey consumed. Journal of Wildlife Management 42: 528-532.

Francisci F. and Guberti V. 1993. Recent trends of wolves in Italy as apparent from kill figures and specimens. [In: Wolves in Europe, status and perspectives. C. Prombergher and W. Schröder, eds]. Munich Wildlife Society, Munich: 91-102.

Frenzel L. D. 1974. Occurrence of moose in food of wolves as revealed by scat analysis: a rewiew of North American studies. Naturaliste Canadienne 101: 467-479

Fritts S. H. and Mech L. D. 1981. Dynamic, movement, and feeding ecology of a newly protected wolf population in northwestern Minnesota. Wildlife Monographs 80: 1-78.

Gasaway W. C., Stephenson R. O., Davis J. L., Shepherd P. E. K. and Burris O. E. 1983. Interrelationships of wolves, prey, and man in interior Alaska. Wildlife Monographs 84: 1-50.

Hall A. M. 1971. Ecology of beaver and selection of prey by wolves in central Ontario. M Sc thesis, University of Toronto (Ontario): 1-116.

Harrington F. H. and Mech L. D. 1982. An analysis of howling response parameters useful for wolf pack censusing. Journal of Wildlife Management 46: 686-693. 
Holleman D. F. and Stephenson R. O. 1981. Prey selection and consumption by Alaskan wolves in winter. Journal of Wildlife Management 45: 620-628.

Jędrzejewska B., Okarma H., Jędrzejewski W. and Miłkowski L. 1994. Effects of exploitation and protection on forest structure, ungulate density and wolf predation in Białowieża Primeval Forest, Poland. Journal of Applied Ecology 31: 664-676.

Jędrzejewski W., Jędrzejewska B. and Szymura A. 1989. Food niche overlaps in a winter community of predators in the Bialowieza primeval forest, Poland. Acta Theriologica 34: 487-496.

Kuyt E. 1972. Food habits of wolves on barrenground caribou range. Canadian Wildlife Service Report 21: $1-36$.

Lorenzini R., Patalano M., Apollonio M. and Mazzarone V. 1993. Genetic variability of roe deer Capreolus capreolus in Italy: electophoretic survey on populations of different origin. [In: Ecological genetics in mammals. G. B. Hartl and J. Markowski, eds]. Acta Theriologica 38, Suppl. 2: 141-151.

Lovari C., Mattioli L., Mazzarone V., Pedone P. and Siemoni N. 1989. A comparison of two censuses methods of roe deer in Apennines mountains. Atti II Seminario Italiano sui Censimenti Faunistici dei Vertebrati. Supplemento alle Ricerche di Biologia della Selvaggina 14: 637-638. [In Italian]

Lovari C., Mattioli L., Mazzarone V., Siemoni N. and Pedone P. 1991. Biometric statistics of two populations of roe deer (Capreolus capreolus L.) in Tuscany, Italy. [In: Ongules/Ungulates 91. F. Spitz, G. Janeau, G. Gonzales and S. Aulagnier, eds]. IRGM, Paris Toulouse: 133-136.

Matteucci C. 1993. Preliminary data on the ecology of a wolf population in northern Italy. [In: Global trends in wildlife management. B. Bobek, K. Perzanowski and W. L. Regelin, eds]. Jagiellonian University, Kraków: 367-370.

Mazzarone V., Siemoni N., Pedone P., Lovari C. and Mattioli L. 1991. A method of red deer (Cervus elaphus) census during the roaring period in a forested area of the northern Appennines (central Italy). [In: Transactions of the XXth International Union of Game Biologist Congress. S. Csanyi and J. Ernhaft, eds]. University of Agricultural Sciences, Godollo. Part 1: 140-145.

Mech L. D. 1970. The wolf: the ecology and behavior of an endangered species. The Natural History Press, Garden City, New York: 1-348.

Mech L. D. and Karns P. D. 1977. Role of the wolf in a deer decline in the Superior National Forest. U.S.D.A. Forest Service Research Paper NC-148: 1-23.

Meriggi A., Rosa P., Brangi A. and Matteucci C. 1991. Habitat use and diet of the wolf in northern Italy. Acta Theriologica 36: 141-151.

Padula M. 1988. [The climate]. [In: Le Foreste di Campigna-Lama nell'Appennino tosco-romagnolo. M. Padula and G. Crudele, eds]. Regione Emilia Romagna, Bologna: 121-143. [In Italian]

Patalano M. and Lovari S. 1993. Food habits and niche overlap of the wolf Canis lupus, L. 1758 and the red fox Vulpes vulpes L. 1758 in a mediterranean mountain area. Revue Ecologie (Terre Vie) 48: 279-293.

Pedone P., Mattioli L., Mattioli S., Siemoni N., Lovari C. and Mazzarone V. 1991. Body growth and fertility in wild boars of Tuscany, central Italy [In: Transactions of the XXth International Union of Game Biologist Congress. S. Csanyi and J. Ernhaft, eds]. University of Agricultural Sciences, Godollo, Part 2: 604-609.

Peterson R. O., Woolington J. D. and Bailey T. N. 1984. Wolves of the Kenai peninsula, Alaska. Wildlife Monograph 88: 1-52.

Petrucci-Fonseca F. and Promberger C. 1993. Population trends of wolves in Portugal. [In: Wolves in Europe. Status and perspectives. C. Prombergher and W. Schröder, eds]. Munich Wildlife Society, Munich: $110-112$.

Ragni B., Mariani L., Inverni A., Armentano L. and Magrini M. 1982. The wolf in Umbria.[In: Atti del Convegno Nazionale "Gruppo Lupo Italia"]. Gruppo Lupo Italia, Civitella Alfedena: 22-36. [In Italian]

Ricklefs R. E. 1980. Ecology. Nelson \& Sons, Sunbury-on-Thames: 1-966.

Salvador A. and Abad P. L. 1987. Food habits of a wolf population (Canis lupus) in Leon province, Spain. Mammalia 51: 45-52. 
Schmid 1963. Natural distribution of mediterranean vegetation. Archivi Botanici e Biogeogeografici Italiani 39: 1-39. [In Italian]

Shelton P. C. 1966. Ecological studies of beavers, wolves and moose in Isle Royale National Park, Michigan. Ph D thesis, Purdue University, Lafayette: 1-308.

Telleria J. C. and Saez-Royuela C. 1989. Ecologia de una poblacion iberica de lobos (Canis lupus). Doñana Acta Vertebrata 16: 105-122.

Thompson D. Q. 1952. Travel, range, and food habits of timber wolves in Wisconsin. Journal of Mammalogy 33: 429-442.

Vila C., Castroviejo J. and Urios V. 1993. The Iberian Wolf in Spain. [In: Wolves in Europe. Status and perspectives. C. Prombergher and W. Schröder, eds]. Munich Wildlife Society, Munich: 104-109.

Voigth D. R., Kolenovsky G. B. and Pimlott D. H. 1976. Changes in summer foods of wolves in central Ontario. Journal of Wildlife Management 40: 663-668.

Received 12 September 1994, accepted 9 October 1995. 